\title{
FKBP51 induces p53-dependent apoptosis and enhances drug sensitivity of human non-small-cell lung cancer cells
}

\author{
YU CHEN $^{1 *}$, ZHIQIANG LIU $^{1 *}$, YUEQUN WANG $^{1 *}$, JIAN ZHUANG $^{2 *}$, YUN PENG $^{1}$, \\ XIAOYANG MO ${ }^{1}$, JIMEI CHEN ${ }^{2}$, YAN SHI ${ }^{1}$, MENGXIONG YU ${ }^{1}$, WANWAN CAI ${ }^{1}$, YAHUAN LI $^{1}$, \\ XIAOLAN ZHU ${ }^{2}$, WUZHOU YUAN ${ }^{1}$, YONGQING LI ${ }^{1}$, FANG LI ${ }^{1}$, ZUOQIONG ZHOU $^{1,2}$, GUO DAI $^{1}$, \\ XIANGLI YE $^{1}$, YONGQI WAN ${ }^{1}$, ZHIGANG JIANG ${ }^{1}$, PING ZHU ${ }^{2}$, XIONGWEI FAN ${ }^{1}$ and XIUSHAN WU ${ }^{1}$ \\ ${ }^{1}$ Center for Heart Development, State Key Lab of Development Biology of Freshwater Fish, Key Lab of \\ MOE for Development Biology and Protein Chemistry, College of Life Sciences, Hunan Normal University, Changsha, \\ Hunan 410006; ${ }^{2}$ Department of Cardiac Surgery, Guangdong Cardiovascular Institute, Guangdong General Hospital, \\ Guangdong Academy of Medical Sciences, Guangzhou, Guangdong 510100, P.R. China
}

Received April 25, 2019; Accepted November 13, 2019

DOI: $10.3892 /$ etm.2020.8450

\begin{abstract}
Lung cancer is one of the most prevalent cancer types worldwide, and non-small-cell lung cancer (NSCLC) accounts for $\sim 85 \%$ of all lung cancer cases. Despite the notable prevalence of NSCLC, the mechanisms underlying its progression remain unclear. The present study investigated the involvement of FK506-binding protein 51 (FKBP51) in NSCLC development and determined the factors associated with FKBP51 modification for NSCLC treatment. Immunohistochemical analysis was performed to analyze FKBP51 expression in human NSCLC tissue samples. Additionally, flow cytometry was performed to observe the apoptosis of FKBP51-overexpressing A549 cells. A dual-luciferase reporter assay was performed to confirm the association between FKBP51 and p53 expression, and western blotting was performed to analyze the effects of FKBP51 on the p53 signaling pathway. Finally, cell viability was measured using a Cell Counting Kit-8 assay. The results suggested FKBP51 downregulation in human lung cancer. Furthermore, apoptosis
\end{abstract}

Correspondence to: Professor Xiushan $\mathrm{Wu}$, Center for Heart Development, State Key Lab of Development Biology of Freshwater Fish, Key Lab of MOE for Development Biology and Protein Chemistry, College of Life Sciences, Hunan Normal University, 36 Lushan South Road, Changsha, Hunan 410006, P.R. China E-mail:xiushanwu@yahoo.com

Professor Ping Zhu, Department of Cardiac Surgery, Guangdong Cardiovascular Institute, Guangdong General Hospital, Guangdong Academy of Medical Sciences, 106 Zhongshan Er Road, Guangzhou, Guangdong 510100, P.R. China

E-mail: tanganqier@163.com

*Contributed equally

Key words: FK506-binding protein 51, non-small-cell lung cancer, p53 signaling pathway, apoptosis, cisplatin rates may be increased in FKBP51-overexpressing A549 cells. Moreover, FKBP51 promoted p53 expression and subsequent p53 signaling pathway activation. These results indicated that FKBP51 promoted A549 cell apoptosis via the p53 signaling pathway. Additionally, FKBP51 enhanced the sensitivity of A549 cells to cisplatin. Collectively, these data suggested that FKBP51 could serve as a biomarker for human lung cancer and can thus be tailored for incorporation into NSCLC therapy in the future.

\section{Introduction}

Lung cancer is the leading cause of cancer-related mortality worldwide, and non-small-cell lung cancer (NSCLC) accounts for $\sim 85 \%$ of all lung cancer cases (1). To date, several management strategies such as surgery, radiochemotherapy, immunotherapy and other targeted approaches have been applied for NSCLC (2). However, the mortality rate of patients with NSCLC remains high $(1,3)$. Therefore, it is imperative to investigate efficient treatment strategies to incorporate into NSCLC treatment.

FK506-binding protein 51 (FKBP51) is a member of the immunophilin family that is involved in multiple signaling pathways, tumorigenesis and chemoresistance $(4,5)$. As a genetic factor regulating the hypothalamic-pituitary-adrenal (HPA) axis, FKBP51 plays an important role in stress regulation $(6,7)$. However, the functions of FKBP51 in the tumorigenesis of lung cancer remains to be elucidated. FKBP51 protein contains two domains: FK506-binding domains (FK1 and FK2) and tetratricopeptide-repeat (TPR) domains. These unique domains contribute to the different roles of FKBP51 in different cancerous tissues $(6,8,9)$. FKBP51 is robustly stimulated by steroid hormones such as progesterone, glucocorticoid and androgen, but not by estrogen (10). Moreover, the TPR domains can form a super complex with a steroid receptor (11); therefore, these domains play important roles in cellular processes. FKBP51 is reportedly overexpressed in prostate cancer and glioma tissues and also contributes to the promotion of tumorigenesis and cancer development (11). Moreover, FKBP51 may promote tumorigenesis by acting on 
cell metastasis (12). Nevertheless, FK506-binding domains could interact with AKT to promote AKT dephosphorylation, thereby hindering cancer development (13-16). FKBP51 is expressed in almost all normal human tissues, including lung tissue, and is overexpressed in patients with melanoma, prostate cancer, lymphoma, head and neck cancer and brain cancer $(5,17)$. By contrast, it is downregulated in endometrial adenocarcinoma, pancreatic cancer colon cancer and testicular cancer (18). Furthermore, FKBP51 can bind to beclin-1, modifying its phosphorylation and protein levels, enhancing the levels of autophagy markers and autophagic flux $(19,20)$.

Up to $50-80 \%$ of patients with NSCLC exhibit inactivation or loss of tumor suppressor p53 $(3,21)$. Moreover, tumor suppressor p53 is a transcription factor that responds to carcinogenic stress $(22,23)$. In addition, mutant p53 cells were found to be sensitive to chemotherapy and to show decreased AKT expression (24,25).p53 may inhibit AKT activation and promote cellular autophagy (26). However, to the best of our knowledge, the association between FKBP51 and cellular apoptosis via the p53 signaling pathway in NSCLC, and the extent to which this association impedes tumorigenesis, remains to be clarified.

In the present study, tissue samples from lung cancer patients were collected, and the association between lung cancer and FKBP51 was examined using immunohistochemistry (IHC). Additionally, the effects of FKBP51 on tumor cell apoptosis were explored, as evidenced by FKBP51 overexpression in the A549 cell line. Finally, the association between FKBP51 and the p53 signaling pathway was studied and the role of FKBP51 in the sensitivity of A549 cells to cisplatin was examined.

\section{Materials and methods}

Human lung carcinoma and healthy lung tissues. The study was approved by the Institutional Ethics Committee of Hunan Normal University. A total of 15 paired primary lung carcinoma tissue specimens and samples of their respective adjacent normal tissues were collected from patients who underwent complete surgical resection from January 2018 to December 2018 at the Hunan Tumor Hospital. All samples were obtained at the time of operation, immediately snap-frozen in liquid nitrogen, and stored at $-80^{\circ} \mathrm{C}$. Patients in this study did not receive chemotherapy or radiation therapy before surgical resection. An experienced pathologist established the pathological diagnosis for each patient. In total, 7 of the 15 patients (age, 48-70 years; 3 women and 12 men) were diagnosed with tumor-node-metastasis (TNM) stage I/II tumors, while the remaining 8 were diagnosed with TNM stage III/IV tumors. Lymph node metastasis was observed in 4 patients. All patients provided their signed informed consent before study participation.

Immunohistochemistry. The collected tissue samples were fixed in $10 \%$ neutral formalin at $4^{\circ} \mathrm{C}$ overnight, embedded in paraffin, and sliced to obtain $4-\mu$ m-thick sections. Immunostaining was performed using the streptavidin peroxidase method. The sections were incubated with monoclonal rabbit anti-FKBP51 antibody (1:250; cat. no. ab126715; Abcam) overnight at $4{ }^{\circ} \mathrm{C}$, followed by incubation with biotinylated goat anti-rabbit immunoglobulin $\mathrm{G}$ secondary antibody (1:500; cat. no. CW0109; Beijing Cwbio Biotech Co., Ltd.) for $30 \mathrm{~min}$ at $37^{\circ} \mathrm{C}$. After washing with PBS, sections were incubated with horseradish peroxidase-conjugated streptavidin-biotin (Servicebio G1211; Wuhan Servicebio Technology Co., Ltd.) and developed at room temperature for 2 min with 3-diaminobenzidine tetrahydrochloride (Sinopharm Chemical Reagent Co., Ltd.). Finally, the samples were lightly counterstained at room temperature for $10 \mathrm{~min}$ with hematoxylin, dehydrated in alcohol, and mounted. The slides were semiquantitatively scored by evaluating the staining intensity and the percentage of stained cells in representative areas. The staining intensity was scored as 0 (no signal), 1 (weak), 2 (moderate), or 3 (high) points. The percentage of cells stained was scored as 1 (1-25\%), $2(26-50 \%), 3(51-75 \%)$, or $4(76-100 \%)$ points. A final score of $0-12$ points was obtained by multiplying the staining intensity by the percentage of cells stained. Adjacent nontumorous tissue samples were designated as having positive FKBP51 expression when a score of $\geq 5$ points was noted. Conversely, samples presenting weak expression (1-4 points) or no expression (0 points) were defined as displaying a lack of FKBP51 expression. All samples were observed using a light microscope (x200 and x400 magnification; Olympus Corporation).

Cell culture. The NSCLC cell line A549 was purchased from the American Type Culture Collection and stored in liquid nitrogen. A549 cells are human alveolar basal epithelial adenocarcinoma cells and are commonly used in lung cancer research (27). A549 cells were maintained at $37^{\circ} \mathrm{C}$ under a humidified atmosphere containing $5 \% \mathrm{CO}_{2}$ and cultured in RPMI 1640 medium supplemented with 10\% FBS (Gibco; Thermo Fisher Scientific, Inc.), with $2.0 \mathrm{mM}$ glutamine, $100 \mu \mathrm{g} / \mathrm{ml}$ ampicillin and $100 \mathrm{U} / \mathrm{ml}$ streptomycin sulfate.

Plasmid construction and transfection. Total RNA from cells was extracted using an EZNA ${ }^{\circledR}$ Total RNA kit I (Omega Bio-Tek, Inc.) according to the manufacturer's instructions. RNA was reverse transcribed to cDNA using the PrimeScript RT Reagent kit (Takara Bio, Inc.). FKBP51 was amplified from cDNA by PCR and subcloned into the pCMV-tag2B (Agilent Technologies, Inc.) plasmid to obtain a FKBP51 expression vector using the ClonExpress II One-Step Cloning kit (Vazyme Biotech Co., Ltd.). PCR was performed using the following primer pair: Forward 5'-ACGACGATAAGAGCC CGGGCATGACTACTGATGAAGGTGC-3' and reverse 5'-ATT AAGGTACCGGGCCCCCCTCATACGTGGCCCTCAGGTT-3'. The following cycling conditions were used: Initial denaturation at $95^{\circ} \mathrm{C}$ for $3 \mathrm{~min}$, followed by 30 cycles of $95^{\circ} \mathrm{C}$ for $30 \mathrm{sec}, 60^{\circ} \mathrm{C}$ for $30 \mathrm{sec}$ and $72^{\circ} \mathrm{C}$ for $90 \mathrm{sec}$, and a final extension at $72^{\circ} \mathrm{C}$ for 5 min. PCR products were obtained using a DNA Gel Recovery kit (Beyotime Institute of Biotechnology). For transfection, A549 cells were seeded in 24-well plates at a density of $2 \times 10^{4}$ cells/well and incubated for $14 \mathrm{~h}$. Then, transfection was performed using the vectors $(0.5 \mu \mathrm{g})$ mixed with Lipofectamine ${ }^{\circledR} 2000$ (Thermo Fisher Scientific, Inc.) at a ratio of 1:2 (volume/volume), according to the manufacturer's specifications.

Dual-luciferase reporter assay. A549 cells in 24-well plates were co-transfected with pCMV-tag2B, pCMV-tag2B-FKBP51 (Agilent Technologies, Inc.), pRL-TK and pGL4.1-p53-LUC (Promega Corporation). The total amount of plasmid was balanced with the empty vector for each transfection using the vectors $(0.5 \mu \mathrm{g})$ mixed with Lipofectamine ${ }^{\circledR} 2000$ (Thermo Fisher Scientific, Inc.) at a ratio of 1:2 (volume/volume). The 

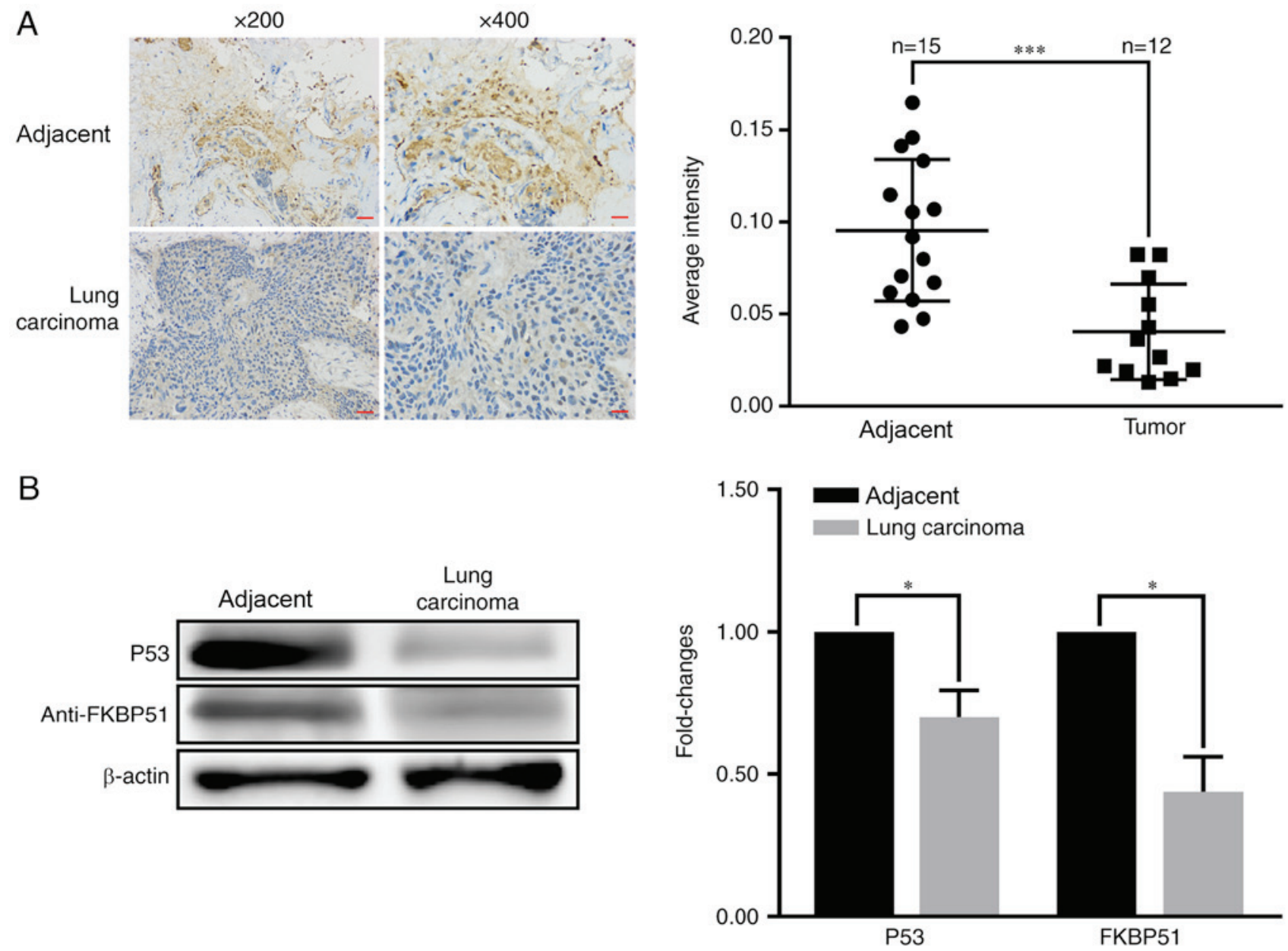

Figure 1. FKBP51 and p53 expression is downregulated in lung cancer. FKBP51 expression was determined using immunohistochemistry and p53 expression was assessed using western blotting. (A) Immunohistochemical staining of FKBP51 in the adjacent and lung carcinoma (x200 and x400 magnification). Representative IHC images of 15 lung carcinoma samples collected from Hunan Tumor Hospital. Scale bar, $20 \mu \mathrm{m}$ for x200 images, $10 \mu \mathrm{m}$ for x400 images. (B) FKBP51 expression in lung cancer tissues and adjacent tissues. (C) Left panel: Western blots of FKBP51 and p53 protein. $\beta$-actin was used as the loading control. Right panel: Quantitative map of protein expression levels. Data were derived from three independent experiments. ${ }^{~} \mathrm{P}<0.05$, ${ }^{* * *} \mathrm{P}<0.001$. FKBP52, FK506-binding protein 51 .

cells were harvested and lysed with the Dual-Luciferase ${ }^{\circledR}$ Reporter Assay System (Promega Corporation) on ice at $24 \mathrm{~h}$ after transfection. Relative luciferase activity against Renilla luciferase activity was used for normalization. The data above were analyzed using GloMax ${ }^{\circledR}$ 20/20 Luminometer (Promega, Inc.). The plasmids pCMV-tag2B were used as negative controls.

Western blotting. To prepare total protein extracts, cells were collected at $48 \mathrm{~h}$ post-transfection and lysed using RIPA buffer (Beijing Cwbio Biotech Co., Ltd.) at $4^{\circ} \mathrm{C}$ for $10 \mathrm{~min}$. Subsequently, the mixture was centrifuged at $12,000 \mathrm{x} \mathrm{g}$ at $4^{\circ} \mathrm{C}$ for $10 \mathrm{~min}$, and the supernatant was transferred to a fresh tube. Total protein concentration was detected using a BCA assay (Beyotime Institute of Biotechnology). Proteins (50 $\mu \mathrm{g})$ were separated by $10 \%$ SDS-PAGE and transferred onto PVDF membranes (EMD Millipore). After blocking in 5\% non-fat milk for $1 \mathrm{~h}$ at room temperature, the membranes were incubated with the appropriate primary antibody overnight at $4^{\circ} \mathrm{C}$, followed by a secondary antibody incubation for $2 \mathrm{~h}$ at room temperature. Bands were visualized with the Tanon 5500 Multi Automatic Chemiluminescence-Fluorescence Image Analysis System (Tanon Science \& Technology Co., Ltd.).
Anti-FLAG primary antibodies were purchased from Abcam (1:1,000; cat. no. ab205606). Anti- $\beta$-actin, -p53, -Bcl-2 and -cleaved caspase-3 were purchased from Cell Signaling Technology, Inc. (1:1,000; cat. nos. 4970, 2527, 4223, 9664, respectively). Goat anti-rabbit IgG-HRP was purchased from Cwbio (1:5,000; cat. no. CW0103S).

Flow cytometry. Apoptosis levels were measured using the FITC-Annexin V Apoptosis Detection kit (Becton, Dickinson and Company). The FKBP51 expression plasmid was transfected into the cells in a culture flask for $48 \mathrm{~h}$. Before testing, the cells were trypsinized, resuspended in $500 \mu \mathrm{l}$ binding buffer [10 mM HEPES (pH 7.4), $140 \mathrm{mM} \mathrm{NaCl}, 1 \mathrm{mM} \mathrm{MgCl} 2,5 \mathrm{mM}$ $\mathrm{KCl}$ and $2.5 \mathrm{mM} \mathrm{CaCl}_{2}$ ] containing $5 \mu \mathrm{l}$ FITC-conjugated Annexin $\mathrm{V}$ and $5 \mu \mathrm{l}$ propidium iodide (PI), and incubated at room temperature in the dark for $10 \mathrm{~min}$. A total of $1 \times 10^{5}$ cells were harvested and analyzed using the BD FACSCalibur ${ }^{\mathrm{TM}}$ flow cytometer (Becton, Dickinson and Company). Following PI excitation with an argon ion laser at a wavelength of $488 \mathrm{~nm}$ and acceptance through a filter at a wavelength of $630 \mathrm{~nm}$, $1 \times 10^{4}$ cells were collected using the forward scatter/side scatter scatterplot method to exclude mutually adherent cells and cell 
A

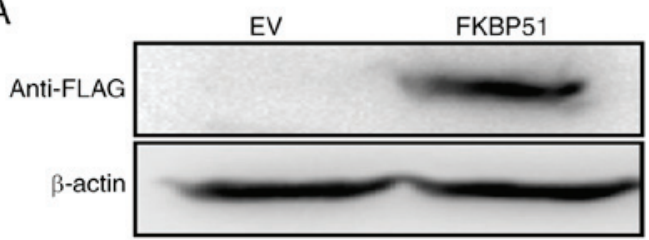

C

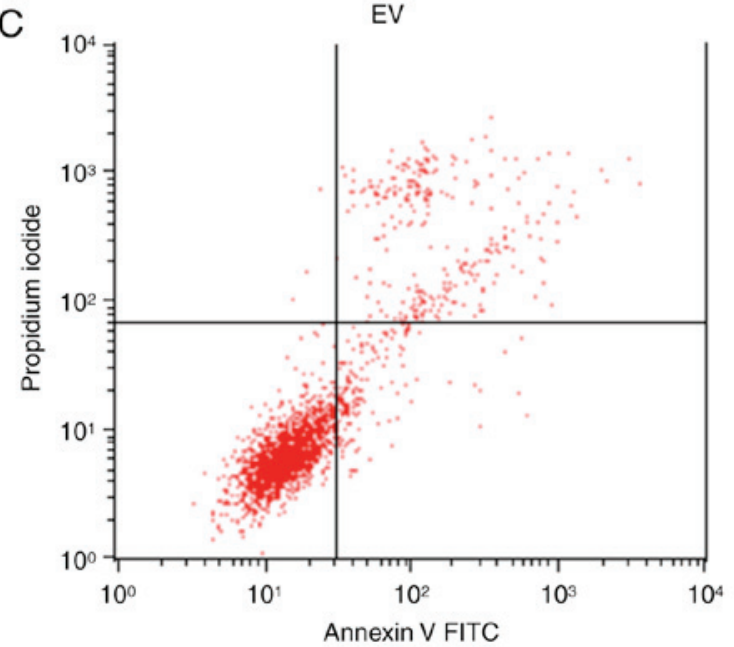

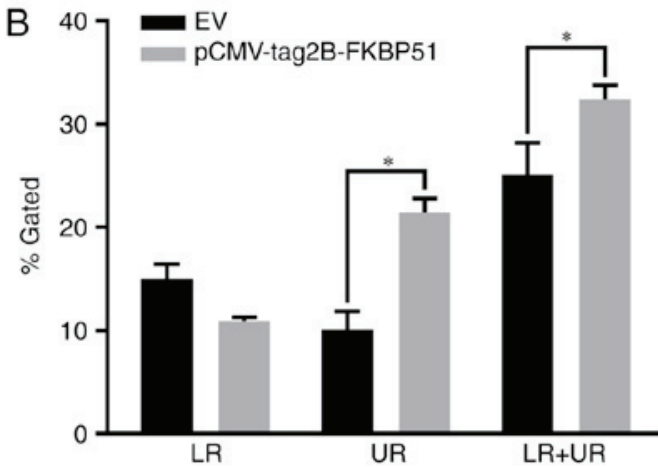

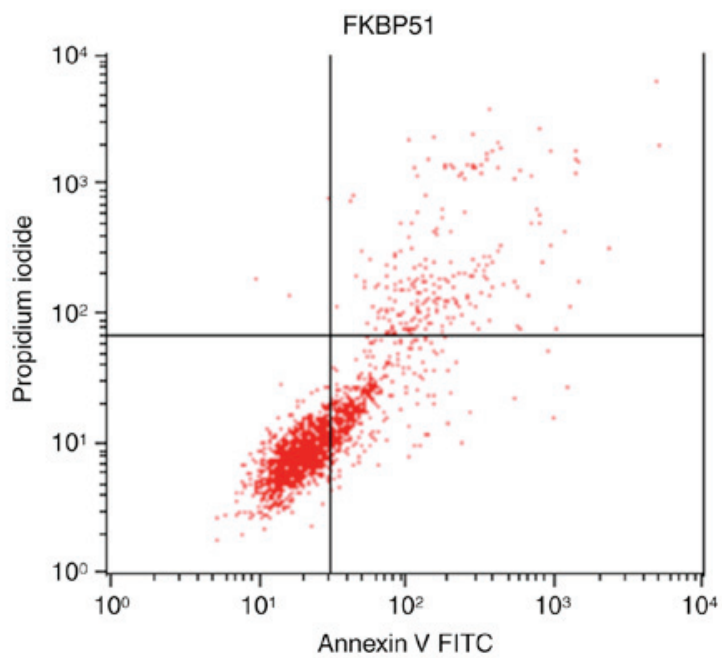

Figure 2. FKBP51 overexpression promotes cellular apoptosis. (A) FKBP51 overexpression in A549 cells was demonstrated by western blotting. $\beta$-actin was used as the loading control. (B) Flow cytometric apoptosis measurement of A549 cells transfected with pCMV-tag2B-FKBP51 and pCMV-tag2B plasmids. (C) Quantitative map of protein expression levels. FKBP51-overexpressing cells showed a higher apoptotic rate compared with control cells. * $<<0.05$. EV, empty vector; LR, early apoptotic cells; UR, late apoptotic and dead cells; LR + UR, all apoptotic cells; FKBP52, FK506-binding protein 51.

debris. The percentage of cells in each phase of cell cycle was presented on the PI fluorescence histogram.

Cell Counting Kit-8 (CCK8) assay. A549 cells were seeded into a 96 -well plate at a density of $5 \times 10^{3} /$ well and cultured in $5 \% \mathrm{CO}_{2}$ atmosphere at $37^{\circ} \mathrm{C}$. Cisplatin (Selleck Chemicals, Inc.) was dissolved in dimethyl sulfoxide (Sigma-Aldrich; Merck KGaA). The cells were cultured for $16 \mathrm{~h}$ before transfection with pCMV-tag2B-FKBP51, followed by treatment with cisplatin $(20 \mu \mathrm{M})$ for $24 \mathrm{~h}$. Finally, CCK8 (MedChemExpress) was added to the plate in the vehicle group. The CCK8 assay was performed according to the manufacturer's guidelines after $4 \mathrm{~h}$ of incubation.

Statistical analysis. SPSS 19.0 software (IBM Corp.) was used for statistical analysis. Results of IHC and clinical correlations were evaluated using the $\chi^{2}$ test. Data are expressed as the mean \pm SD. Student's t-test was used to evaluate the differences between the two groups, with $\mathrm{P}<0.05$ considered to indicate a statistically significant difference.

\section{Results}

FKBP51 and p53 expression are downregulated in human lung carcinoma. A total of 15 paired primary lung carcinoma tissue samples were collected to investigate the role of FKBP51 in lung carcinoma development and IHC was performed to examine the association between FKBP51 expression and lung cancer development. FKBP51 expression in lung cancer tissue samples was significantly lower compared with that in adjacent tissues (Fig. 1A). Western blotting revealed that FKBP51 and p53 levels were decreased in lung carcinoma tissues compared with adjacent tissues (Fig. 1B).

FKBP51 overexpression promotes A549 cell apoptosis. Since FKBP51 expression was downregulated in lung carcinoma tissue, it was hypothesized that this protein may play a role in lung cancer development. To test this hypothesis, FKBP51 was overexpressed in A549 cells and cellular apoptosis was detected using flow cytometry. FLAG expression significantly increased after transfection compared with empty vector controls, indicating that FKBP51 was successfully overexpressed in A549 cells (Fig. 2A). Flow cytometry revealed that FKBP51 overexpression in A549 cells significantly promoted cellular apoptosis compared with empty vector controls (Fig. 2B and C).

FKBP51 promotes A549 cell apoptosis through activation of the p53 signaling pathway. Since FKBP51 was shown to promote A549 cell apoptosis, the expression of proteins known to be involved in tumorigenesis pathways was investigated to further elucidate the molecular mechanisms underlying this process. The p53 signaling pathway was found to be involved 


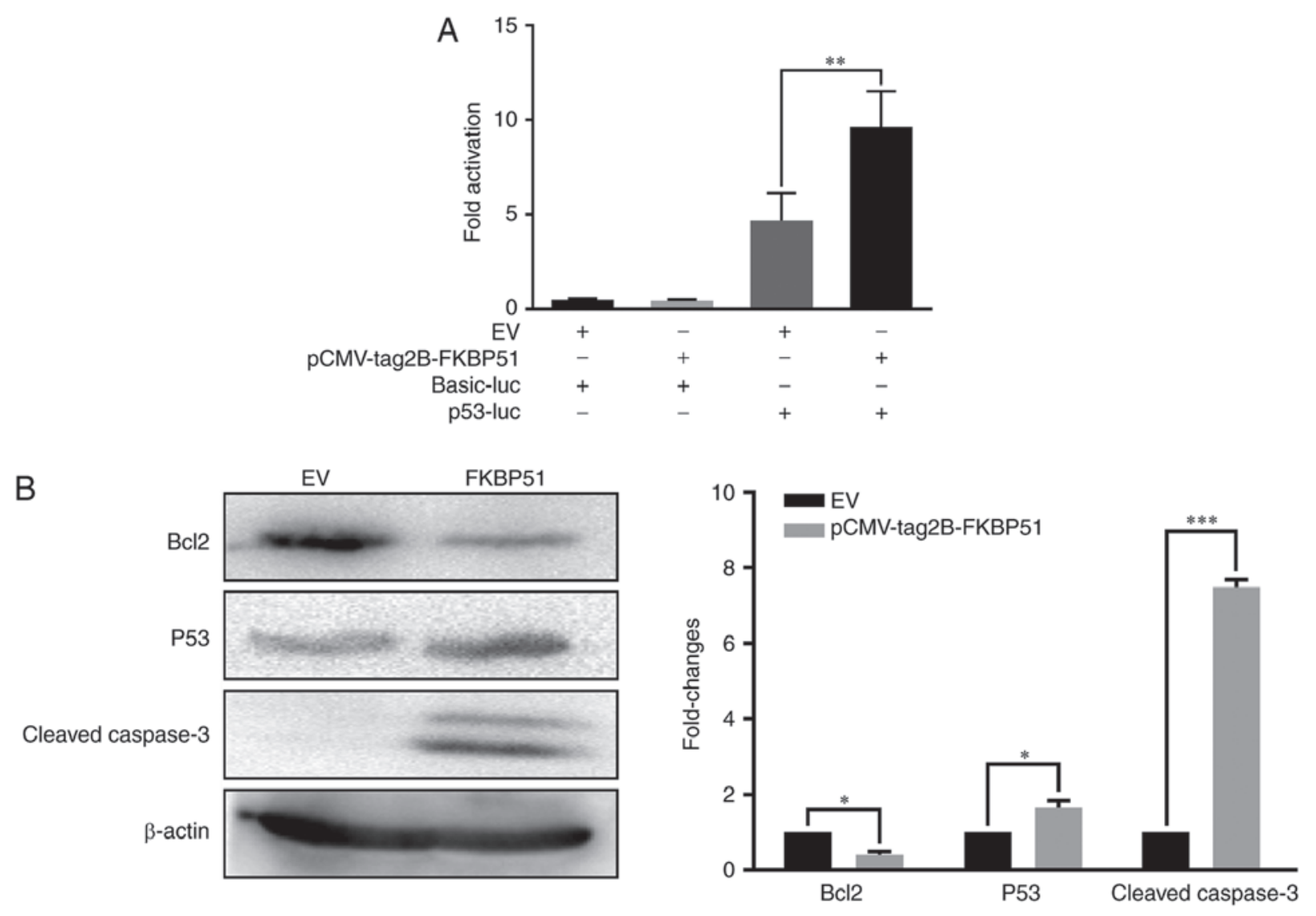

Figure 3. FKBP51 promotes A549 cell apoptosis by activating the extracellular p53 signaling pathway. (A) Dual-luciferase reporter assay of A549 cells transfected with plasmid combined with pCMV-tag2B, pCMV-tag2B-FKBP51, and pGL4.1-p53-LUC. (B) Left panel: Levels of p53, Bcl-2, and caspase-3 in FKBP51-overexpressing and control cells measured by western blotting; Right panel: Quantitative map of protein expression levels. Data were derived from three independent experiments. ${ }^{*} \mathrm{P}<0.05,{ }^{* *} \mathrm{P}<0.01,{ }^{* * *} \mathrm{P}<0.001$. EV, empty vector; FKBP52, FK506-binding protein 51.

in apoptosis regulation by FKBP51. A dual-luciferase reporter assay was performed to examine the association between FKBP51 and p53. p53 levels were significantly increased in FKBP51-overexpressing A549 cells compared with control cells (Fig. 3A). To further confirm whether the p53 signaling pathway was involved in FKBP51-mediated promotion of apoptosis, p53 levels were detected using western blotting. p53 and caspase-3 levels were significantly increased while Bcl-2 levels were significantly decreased in FKBP51-overexpressing A549 cells compared with control cells (Fig. 3B). These results suggested that FKBP51 functions by activating the p53 signaling pathway in A549 cells.

FKBP51 contributes to the sensitivity of A549 cells to cisplatin. The resistance of tumor cells to drugs has been known to hinder cancer treatment to a certain extent (18). The cell viability of A549 cells was tested using a CCK8 assay. FKBP51-overexpressing A549 cells showed a significantly lower survival rate following cisplatin exposure compared with empty vector controls (Fig. 4). This finding suggested that FKBP51 improves the sensitivity of A549 cells to cisplatin.

\section{Discussion}

Although the diagnosis and treatment of NSCLC has been well explored, this malignant condition only has a 5-year survival rate of $<15 \%$ (28). A combination of cisplatin-based chemotherapy

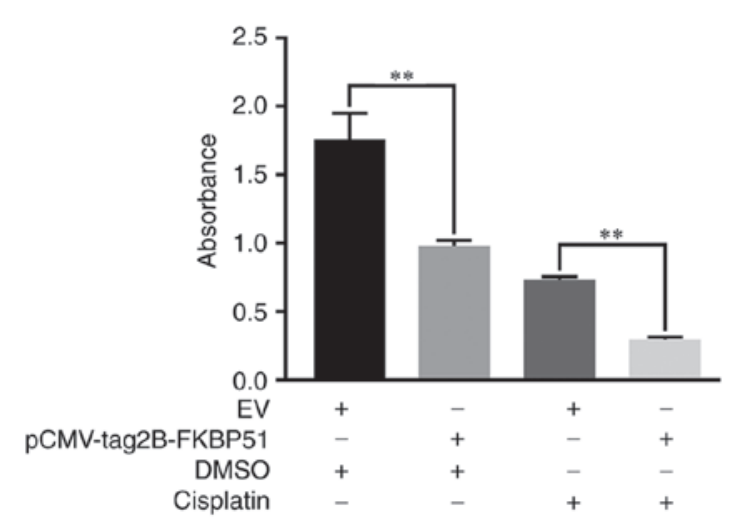

Figure 4. FKBP51 increases the sensitivity of A549 cells to cisplatin Proliferation rate of FKBP51-overexpressing A549 cells transfected with empty vector or treated with cisplatin, as measured by a CCK- 8 assay. Data were derived from three independent experiments. ${ }^{* *} \mathrm{P}<0.01$. EV, empty vector; CCK-8, Cell Counting Kit-8; FKBP52, FK506-binding protein 51.

and EGFR tyrosine kinase inhibitors (TKIs) represents a relatively common approach to NSCLC treatment; however, drug resistance is an inevitable factor (29). Moreover, substantial evidence indicates that FKBP51 plays an important role in stress biology, metabolism, pain signaling and the ability to upregulate gene expression via stress and glucocorticoid hormones $(4,7,30)$. Meanwhile, studies have shown that FKBP51 may be a potential 
target for prostate cancer treatment $(10,11,31)$. In the present study, FKBP51 expression was detected in human lung cancer and healthy tissues using IHC. FKBP51 expression in NSCLC was significantly lower compared with healthy lung tissues. This effect revealed that lower FKBP51 expression was associated with lung cancer development. Subsequently, FKBP51 expression was examined in lung cancer tissues using western blotting. It was found that FKBP51 and tumor suppressor p53 were poorly expressed in lung carcinoma tissues compared with adjacent tissues, suggesting that FKBP51 plays a role in inhibiting lung cancer development. However, the potential molecular mechanisms of FKBP51 in NSCLC remain unclear.

To investigate whether FKBP51 was involved in apoptosis in lung cancer, FKBP51 was overexpressed in A549 cells. The results showed that FKBP51 plays a key role in the regulation of apoptosis in irradiated melanoma cells and FKBP51 was regarded as a candidate marker for the identification of suitable melanoma tumors $(19,32)$. As previously mentioned, FKBP51 may be associated with apoptosis in melanomas. However, to our knowledge, no study on FKBP51 inducing apoptosis in lung cancer has been reported. In this present study, the fusion protein FLAG-FKBP51 was overexpressed in A549 cells. FKBP51 overexpression resulted in a significant increase in the number of apoptotic A549 cells, suggesting that FKBP51 inhibits lung cancer development by promoting cellular apoptosis.

FKBP51 inhibits AKT activation, leading to the inhibition of cell proliferation in endometrial adenocarcinomas (15). Furthermore, FKBP51 binds to beclin-1, thereby promoting cell apoptosis in melanoma cells (19). p53 inactivation promotes cell apoptosis by suppressing Bcl-2 activity and promoting caspase-3 expression (30,33-35). Bcl-2 binds to $\mathrm{p} 53$ to inhibit its activity and thus inhibit apoptosis $(36,37)$. Caspase-3 stimulates cell death via apoptosis $(25,38,39)$. These studies revealed that the FKBP51 was involved in the P53 signaling pathway and induces and apoptotic phenotype in cancer cells. Thus, the flow cytometry results demonstrated that FKBP51 may promote apoptosis in lung cancer cells and inhibits NSCLC development. Moreover, FKBP51 was found to promote p53 expression. Among the downstream effectors, Bcl-2 was downregulated and caspase-3 was upregulated. These results suggested that FKBP51 blocks NSCLC development by promoting A549 cell apoptosis via the p53 signaling pathway.

The resistance of tumor cells to drugs often reduces the efficacy of chemotherapy. Thus, improving the sensitivity of tumor cells to drugs is of great significance in the treatment of cancer $(40,41)$. Previous studies have shown that FKBP51 increases the sensitivity of pancreatic cancer to chemotherapy drugs $(13,16)$. Chemotherapy is one of the key options available for the treatment of NSCLC (42). Thus, improving the drug sensitivity of NSCLC is crucial. Our study showed that the FKBP51 acts as an transducer of the chemotherapy drug cisplatin. When FKBP51 is overexpressed, the sensitivity of NSCLC cells to cisplatin was increased, which is of benefit for clinical treatment of this cancer type.

In conclusion, FKBP51 is downregulated in human lung cancer tissues. FKBP51 overexpression in A549 cells promoted cellular apoptosis. Additionally, FKBP51 increased enhanced the activity of the p53 signaling pathway, suggesting that FKBP51 can block lung cancer progression via this pathway. Finally, FKBP51-overexpressing A549 cells showed increased sensitivity to cisplatin. Collectively, our results suggested that FKBP51 can be a therapeutic target for NSCLC.

\section{Acknowledgements}

Not applicable.

\section{Funding}

This study was supported in part by grants from the National Natural Science Foundation of China (grant nos. 81470449, 81670290, 81470377, 31872315, 31572349, 81670288, 81700338 and 81570279), the Cooperative Innovation Center of Engineering and New Products for Developmental Biology of Hunan Province (grant no. 2013-448-6), National Key Research and Development Program of China (grant nos. 2018YFA0108700 and 2017YFA0105602), NSFC Projects of International Cooperation and Exchanges (grant no. 81720102004), The Research Team Project of Natural Science Foundation of Guangdong Province of China (grant no. 2017A030312007), Science and Technology Planning Projects of Guangdong Province of China (grant nos. 2017A070701013, 2017B090904034, 2017030314109, 2019B020230003), the Special Project of Dengfeng Program of Guangdong Provincial People's Hospital (grant no. DFJH201802), the Key Program of Guangzhou Science Research Plan (grant no. 805212639211). Hunan Provincial Natural Science Foundation of China (grant nos. 2015JJ3087 and 2018JJ2666) and the Scientific Research Fund of Hunan Provincial Education Department (grant no. 18A028).

\section{Availability of data and materials}

The datasets used and/or analyzed during the present study are available from the corresponding author on reasonable request.

\section{Authors' contributions}

YC contributed to acquisition of data, revision of the manuscript, ZL, YQW and JZ contributed to the acquisition of data and writing the manuscript, YP, XM, JC, YS, MY, WC, YHL, XZ, WY, YQL, FL, ZZ, GD,XY and YW contributed to the acquisition of data, $\mathrm{ZJ}$ and PZ contributed to the analysis and interpretation of data, $\mathrm{XF}$ contributed to the acquisition of data and revision of the manuscript, XW contributed to the conception, design, revision of the manuscript and the acquisition of data.

\section{Ethics approval and consent to participate}

All patients provided their written informed consent and agreed to the usage of their samples in scientific research. All human procedures were approved by the Ethics Committee of Hunan Normal University (Changsha, China). All animal procedures were performed in accordance with the Guidelines for Care and Use of Laboratory Animals of Hunan Normal University and the experiments were approved by the Animal Ethics Committee of Hunan Normal University.

\section{Patient consent for publication}

Not applicable. 


\section{Competing interests}

The authors declare that they have no competing interests.

\section{References}

1. DeSantis CE, Siegel RL, Sauer AG, Miller KD, Fedewa SA, Alcaraz KI and Jemal A: Cancer statistics for African Americans, 2016: Progress and opportunities in reducing racial disparities. CA Cancer J Clin 66: 290-308, 2016.

2. Hirsch FR, Suda K, Wiens J and Bunn PA Jr: New and emerging targeted treatments in advanced non-small-cell lung cancer. Lancet 388: 1012-1024, 2016.

3. Cancer Genome Atlas Research Network: Comprehensive molecular profiling of lung adenocarcinoma. Nature 511: 543-550, 2014

4. Hähle A, Merz S, Meyners C and Hausch F: The many faces of FKBP51. Biomolecules 9: E35, 2019.

5. Staibano S, Mascolo M, Ilardi G, Siano M and De Rosa G: Immunohistochemical analysis of FKBP51 in human cancers. Curr Opin Pharmacol 11: 338-347, 2011.

6. Romano S, Di Pace A, Sorrentino A, Bisogni R, Sivero L and Romano MF: FK506 binding proteins as targets in anticancer therapy. Anticancer Agents Med Chem 10: 651-656, 2010.

7. Stechschulte LA and Sanchez ER: FKBP51-a selective modulator of glucocorticoid and androgen sensitivity. Curr Opin Pharmacol 11: 332-337, 2011.

8. Cioffi DL, Hubler TR and Scammell JG: Organization and function of the FKBP52 and FKBP51 genes. Curr Opin Pharmacol 11: 308-313, 2011.

9. Wang L: FKBP51 regulation of AKT/protein kinase B phosphorylation. Curr Opin Pharmacol 11: 360-364, 2011.

10. Jääskeläinen T, Makkonen $\mathrm{H}$ and Palvimo JJ: Steroid up-regulation of FKBP51 and its role in hormone signaling. Curr Opin Pharmacol 11: 326-331, 2011.

11. Ni L, Yang CS, Gioeli D, Frierson H, Toft DO and Paschal BM: FKBP51 promotes assembly of the Hsp90 chaperone complex and regulates androgen receptor signaling in prostate cancer cells. Mol Cell Biol 30: 1243-1253, 2010.

12. Takaoka M, Ito S, Miki Y and Nakanishi A: FKBP51 regulates cell motility and invasion via RhoA signaling. Cancer Sci 108 : 380-389, 2017.

13. Hou J and Wang L: FKBP5 as a selection biomarker for gemcitabine and Akt inhibitors in treatment of pancreatic cancer PLoS One 7: e36252, 2012.

14. Pei H,Li L,Fridley BL, Jenkins GD, Kalari KR,Lingle W, Petersen G, Lou $\mathrm{Z}$ and Wang L: FKBP51 affects cancer cell response to chemotherapy by negatively regulating Akt. Cancer Cell 16: 259-266, 2009.

15. Dong J,Jiao Y,Mu W,Lu B, Wei M,Sun L,Hu S, Cui B, Liu X, ChenZ and Zhao Y: FKBP51 decreases cell proliferation and increases progestin sensitivity of human endometrial adenocarcinomas by inhibiting Akt. Oncotarget 8: 80405-80415, 2017.

16. Luo K, Li Y, Yin Y, Li L, Wu C, Chen Y, Nowsheen S, Hu Q, Zhang L, Lou Z and Yuan J: USP49 negatively regulates tumorigenesis and chemoresistance through FKBP51-AKT signaling. EMBO J 36: 1434-1446, 2017.

17. Fagerberg L, Hallström BM, Oksvold P, Kampf C, Djureinovic D, Odeberg J, Habuka M, Tahmasebpoor S, Danielsson A, Edlund $\mathrm{K}$, et al: Analysis of the human tissue-specific expression by genome-wide integration of transcriptomics and antibody-based proteomics. Mol Cell Proteomics 13: 397-406, 2014.

18. Li L, Lou Z and Wang L: The role of FKBP5 in cancer aetiology and chemoresistance. Br J Cancer 104: 19-23, 2011.

19. RomanoS,D'Angelillo A,Pacelli R,StaibanoS,De LunaE,Bisogni R, Eskelinen EL, Mascolo M, Calì G, Arra C and Romano MF: Role of FK506-binding protein 51 in the control of apoptosis of irradiated melanoma cells. Cell Death Differ 17: 145-157, 2010.

20. Gassen NC,Hartmann J, Schmidt MV and Rein T:FKBP5/FKBP51 enhances autophagy to synergize with antidepressant action. Autophagy 11: 578-580, 2015

21. Cancer Genome Atlas Research Network: Comprehensive genomic characterization of squamous cell lung cancers. Nature 489 : 519-525, 2012.

22. Vogelstein B, Lane D and Levine AJ: Surfing the p53 network. Nature 408: 307-310, 2000

23. Donzelli S, Strano S and Blandino G: YAP and p73: A Matter of mutual specificity in tumor suppression. The Hippo Signaling Pathway Cancer 147-172, 2013.
24. Makkonen H, Kauhanen M, Paakinaho V, Jääskeläinen T and Palvimo JJ: Long-range activation of FKBP51 transcription by the androgen receptor via distal intronic enhancers. Nucleic Acids Res 37: 4135-4148, 2009.

25. Kim YY, Jee HJ, Um JH, Kim YM, Bae SS and Yun J: Cooperation between p21 and Akt is required for p53-dependent cellular senescence. Aging Cell 16: 1094-1103. 2017.

26. Cordani M, Butera G, Pacchiana R and Donadelli M: Molecular interplay between mutant p53 proteins and autophagy in cancer cells. Biochim Biophys Acta Rev Cancer 1867: 19-28, 2017.

27. Lieber M, Smith B, Szakal A, Nelson-Rees W and Todaro G: A continuous tumor-cell line from a human lung carcinoma with properties of type II alveolar epithelial cells. Int J Cancer 17: 62-70, 1976

28. Jemal A, Murray T, Ward E, Samuels A, Tiwari RC, Ghafoor A, Feuer EJ and Thun MJ: Cancer Statistics, 2005. CA Cancer J Clin 55: 10-30, 2005.

29. Wang L, Ma L, Xu F, Zhai W, Dong S, Yin L, Liu J and Yu Z: Role of long non-coding RNA in drug resistance in non-small cell lung cancer. Thorac Cancer 9: 761-768, 2018

30. Balsevich G, Häusl AS, Meyer CW, Karamihalev S, Feng X, Pöhlmann ML, Dournes C, Uribemarino A, Santarelli S, Labermaier C: Stress-responsive FKBP51 regulates AKT2-AS160 signaling and metabolic function. Nature Communications ,8 (1): 1725. 2017.

31. Velasco AM, Gillis KA, Li Y, Brown EL, Sadler TM, Achilleos M, Greenberger LM, Frost P, Bai W and Zhang Y: Identification and validation of novel androgen-regulated genes in prostate cancer. Endocrinology 145: 3913-3924, 2004.

32. Romano S, D'Arrigo P, Tufano M, Staibano S, Rea A, Merolla F, Ilardi G, Petrella A and Romano MF: TRAF2 and FKBP51 as possible markers for identification of suitable melanoma tumors for tumor necrosis factor- $\alpha$ inhibition. Melanoma Res 29: 145-150, 2019.

33. Chen J, Xie F, Zhang L and Jiang WG: iASPP is over-expressed in human non-small cell lung cancer and regulates the proliferation of lung cancer cells through a p53 associated pathway. BMC Cancer 10: 694, 2010.

34. Fu X, Xu L, Qi L, Tian H, Yi D, Yu Y, Liu S, Li S, Xu Y and Wang C: BMH-21 inhibits viability and induces apoptosis by p53-dependent nucleolar stress responses in SKOV3 ovarian cancer cells. Oncol Rep 38: 859-865, 2017.

35. Walsh JG, Cullen SP, Sheridan C, Lüthi AU, Gerner C and Martin SJ: Executioner caspase- 3 and caspase-7 are functionally distinct proteases. Proc Natl Acad Sci USA 105: 12815-12819, 2008.

36. Chipuk JE, Moldoveanu T, Llambi F, Parsons MJ and Green DR: The BCL-2 family reunion. Mol Cell 37: 299-310, 2010.

37. Chee JL, Saidin S, Lane DP, Leong SM, Noll JE, Neilsen PM, Phua YT, Gabra H and Lim TM: Wild-type and mutant p53 mediate cisplatin resistance through interaction and inhibition of active caspase-9. Cell Cycle 12: 278-288, 2013.

38. Kato S, Han SY, Liu W, Otsuka K, Shibata H, Kanamaru R and Ishioka C: Understanding the function-structure and function-mutation relationships of p53 tumor suppressor protein by high-resolution missense mutation analysis. Proc Natl Acad Sci USA 100: 8424-8429, 2003.

39. Feng X, Liu H, Zhang Z, Gu Y, Qiu H and He Z: Annexin A2 contributes to cisplatin resistance by activation of JNK-p53 pathway in non-small cell lung cancer cells. J Exp Clin Cancer Res 36: 123, 2017.

40. Sarin N, Engel F, Kalayda GV, Mannewitz M, Cinatl J Jr, Rothweiler F, Michaelis M, Saafan H, Ritter CA, Jaehde U and Frötschl R: Cisplatin resistance in non-small cell lung cancer cells is associated with an abrogation of cisplatin-induced $\mathrm{G} 2 / \mathrm{M}$ cell cycle arrest. PLoS One 12: e0181081, 2017.

41. Wang G, Reed E and Li QQ: Molecular basis of cellular response to cisplatin chemotherapy in non-small cell lung cancer (Review). Oncol Rep 12: 955-965, 2004.

42. Schiller JH, Harrington D, Belani CP, Langer C, Sandler A, Krook J, Zhu J and Johnson DH; Eastern Cooperative Oncology Group: Comparison of four chemotherapy regimens for advanced non-small-cell lung cancer. N Engl J Med 346: 92-98, 2002.

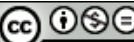

This work is licensed under a Creative Commons Attribution-NonCommercial-NoDerivatives 4.0 International (CC BY-NC-ND 4.0) License. 